\title{
Spatial and Temporal Distribution of Stresses Associated with the Aftershock Sequence of a Moderate Earthquake and Volcanic Eruption near the Izu Peninsula, Japan
}

\author{
Shigeo Mori, ${ }^{1, *}$ Kazuhiko Goto, ${ }^{2}$ Keiichi Fukui, ${ }^{1}$ \\ Ośamu Nagaoka, ${ }^{3}$ Shinichiro Matsuda, ${ }^{3}$ Takeshi Hachimine, ${ }^{3}$ \\ and Kazumitsu Yoshikawa ${ }^{3}$ \\ ${ }^{1}$ Meteorological Research Institute, Nagamine, Tsukuba 305, Japan \\ ${ }^{2}$ Faculty of Science, Kagoshima University, Kagoshima 890, Japan \\ ${ }^{3}$ Japan Meteorological Agency, Chiyoda-ku, Tokyo 100, Japan
}

In July, 1989, a seismic swarm, including an $M_{\mathrm{L}} 5.5$ mainshock on July 9 , occurred east of Izu Peninsula, central Japan. Temporary seismic stations were deployed from July 13 to July 16; during this period, a submarine eruption and the largest aftershock $\left(M_{\mathrm{L}} 4.8\right)$ occurred. Seismic activity during the period was analyzed using hypocenters and focal mechanism solutions obtained from both temporary and routine earthquake observations. The spatial and temporal distribution of solutions indicate that strike-slip and normal events are segregated in space and time and that there was a local stress field within limited spatial and temporal windows.

The spatial and temporal distribution of solutions obtained suggests that the magma related to the submarine eruption penetrated the mainshock source area and filled the deeper part of the eastern half of the study area. This magma penetration induced a local tensile stress which reached to within $1.5 \mathrm{~km}$ of the surface after the largest aftershock, and then decreased rapidly and diminished rapidly after the end of the study period. The northwestern end of the mainshock source area was temporarily controlled by redistributed local stresses induced by the mainshock.

\section{Introduction}

A complex tectonic regime exists on the south coast of Honshu, central Japan, where the Philippine Sea, Pacific, and Eurasian plates converge. While the Philippine Sea plate generally subducts under Eurasia with a convergence rate of $3 \mathrm{~cm} /$ year at an azimuth of $\mathrm{N} 54^{\circ} \mathrm{W}$ in this region (Seno, 1977), a small portion of the Philippine Sea plate, in a region bounded by the Suruga and Sagami troughs, is thought to be colliding with, rather than subducting under, the Eurasian plate (Fig. 1a) due to the presence of a buoyant volcanic arc (e.g., Ukawa, 1991). This colliding region is called the Izu block

Received September 24, 1992; Accepted July 21, 1993

* To whom correspondence should be addressed. 


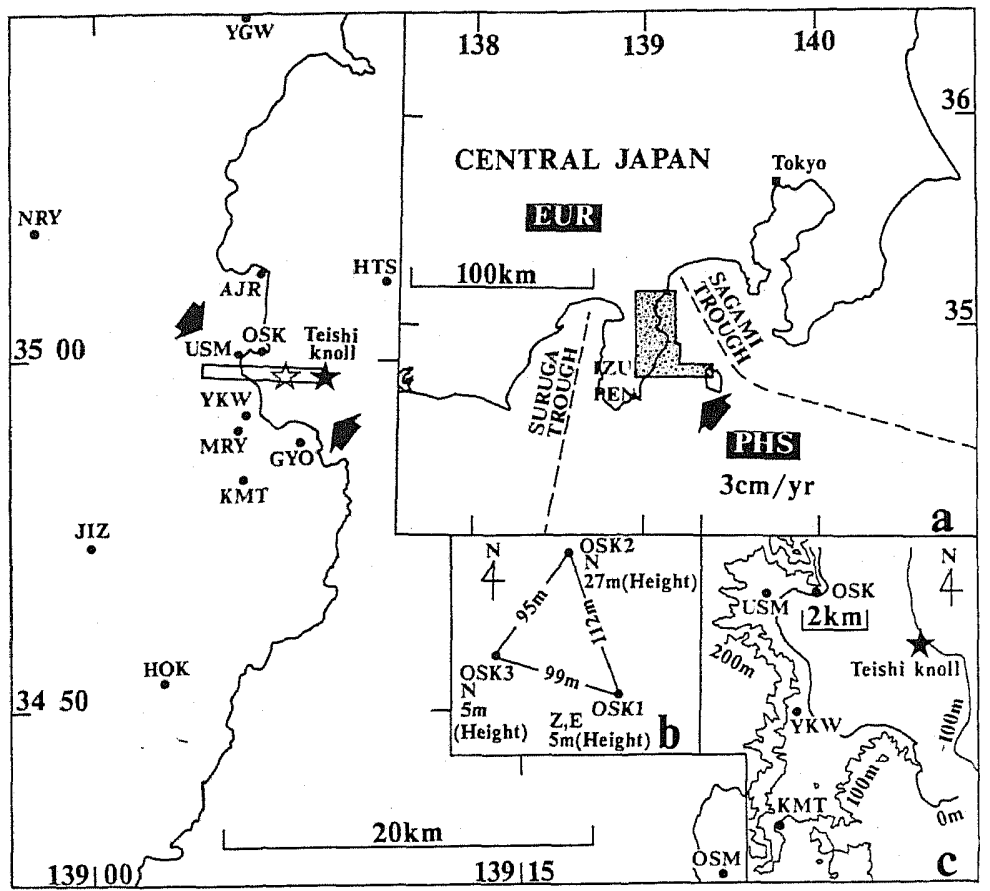

Fig. 1. Station locations and index tectonic setting map. The locations of stations used in this study are shown as solid dots. The locations of the July 9, 1989, mainshock and the submarine eruption at Teishi knoll are shown by the open and solid stars, respectively. The mainshock source area is shown by the rectangle and the regional tectonic stress orientation (Tsukahara and Kobayashi, 1991; Ukawa, 1991) is shown by the two large arrows. Inset (a) shows the location of the study area (stippled) relative to tectonic features and plate boundaries. The relative motion of the Philippine Sea plate (PHS) relative to the Eurasian plate (EUR) (Seno, 1977) is shown by the arrow. Inset (b) shows the seismograph locations at OSK and the components operated at each site ( $Z$, vertical; $E$, east-west; and $N$, north-south). Inset (c) shows topographical features around station OSK. Bathymetry and the location of Teishi knoll is after Maritime Safety Agency (1990). The contour interval is $100 \mathrm{~m}$.

and forms the northernmost section of the Izu-Bonin volcanic arc, produced by the subduction of the Pacific plate beneath the Philippine Sea plate. Numerous volcanoes and submarine volcanic knolls are found on and offshore of eastern Izu Peninsula (Oshima et al., 1991). Although no historic eruptions have been previously reported, repeated seismic swarms have occurred since 1978.

The Izu block is also pulled by the slab-pull force of the subducting portion of the Philippine Sea plate along Sagami trough (Ukawa, 1991). Tsukahara and Ikeda (1991) defined stress provinces in this region based on a compilation of data on crustal stress directions measured in situ and by averaging $\mathrm{P}$-axis orientations from focal mechanisms 
of shallow earthquakes in the central part of Japan. The eastern part of Izu Peninsula is considered as one stress province having an average trajectory of the maximum horizontal stress of $\mathrm{N} 45-55^{\circ} \mathrm{W}$ (Tsukahara and Kobayashi, 1991; Ukawa, 1991).

A seismic swarm began on June 30,1989, to the east of Izu Peninsula in central Japan. The largest earthquake in the swarm (hereafter, the mainshock) was an $M_{\mathbf{L}} 5.5$ event which occurred on July 9 at 02:09 UTC. This swarm has been particularly well studied (Ida and Mizoue, 1991) due to its association with a submarine eruption which formed Teishi knoll (Maritime Safety Agency, 1990; Oshima et al., 1991) and the dense network of seismic networks in the region. This paper summarizes the results primarily from a temporary network deployed by the Meteorological Research Institute in the epicentral region of the swarm (Fig. 1) starting at 08:00 UTC on July 13 and continuing until 03:00 UTC on July 16. During the period of this deployment, the eruption at Teishi knoll and the largest aftershock $\left(M_{\mathrm{L}} 4.8\right)$ occurred and our network including other institutes' stations was that nearest to the activity and had the highest station density. These factors allow us to perform a detailed analysis of the seismicity and stresses in the swarm region and contribute to the understanding of seismic source processes.

Hypocenters and focal mechanisms were determined using data from our temporary network supplemented by data of the Japan Meteorological Agency (JMA), National Research Institute for Earth Science and Disaster Prevention (NIED), Earthquake Research Institute (ERI), and Building Research Institute (BRI). We present data which reveal aspects of temporal and spatial changes in the stress field in the area of the swarm, and their relationship to the mainshock and to the Teishi knoll eruption.

\section{Data}

Thirteen temporary and permanent stations were used in a deployment by the Meteorological Research Institute and other institutes. At Osaki (OSK), three separate

Table 1. Velocity structure used in this study.

\begin{tabular}{|c|c|}
\hline Velocity $(\mathrm{km} / \mathrm{s})$ & Depth $(\mathrm{km})$ \\
\hline $\begin{array}{c}\cdots \cdots \cdots \cdots \cdots \cdots \cdots \\
2.60\end{array}$ & 0.0 \\
\hline $\begin{array}{c}\cdots \cdots \cdots \cdots \cdots \cdots \cdots \cdots \\
4.20\end{array}$ & 0.3 \\
\hline$\underset{5.30}{\cdots \cdots \cdots \cdots \cdots}$ & 2.0 \\
\hline $\begin{array}{c}\cdots .00 \\
6.00 \cdots \cdots \cdots \cdots\end{array}$ & 5.0 \\
\hline $\begin{array}{c}\cdots \cdots \cdots \cdots \cdots \cdots \cdots \\
6.80\end{array}$ & 16.0 \\
\hline $\begin{array}{c}\cdots \cdots \cdots \cdots \cdots \cdots \cdots \cdots \\
7.80\end{array}$ & 32.0 \\
\hline
\end{tabular}

$\mathrm{P}$-wave velocities in $\mathrm{km} / \mathrm{s}$ from Yoshii et al. (1986) and Ikami (1977).

Vol. 41, No. 3, 1993 


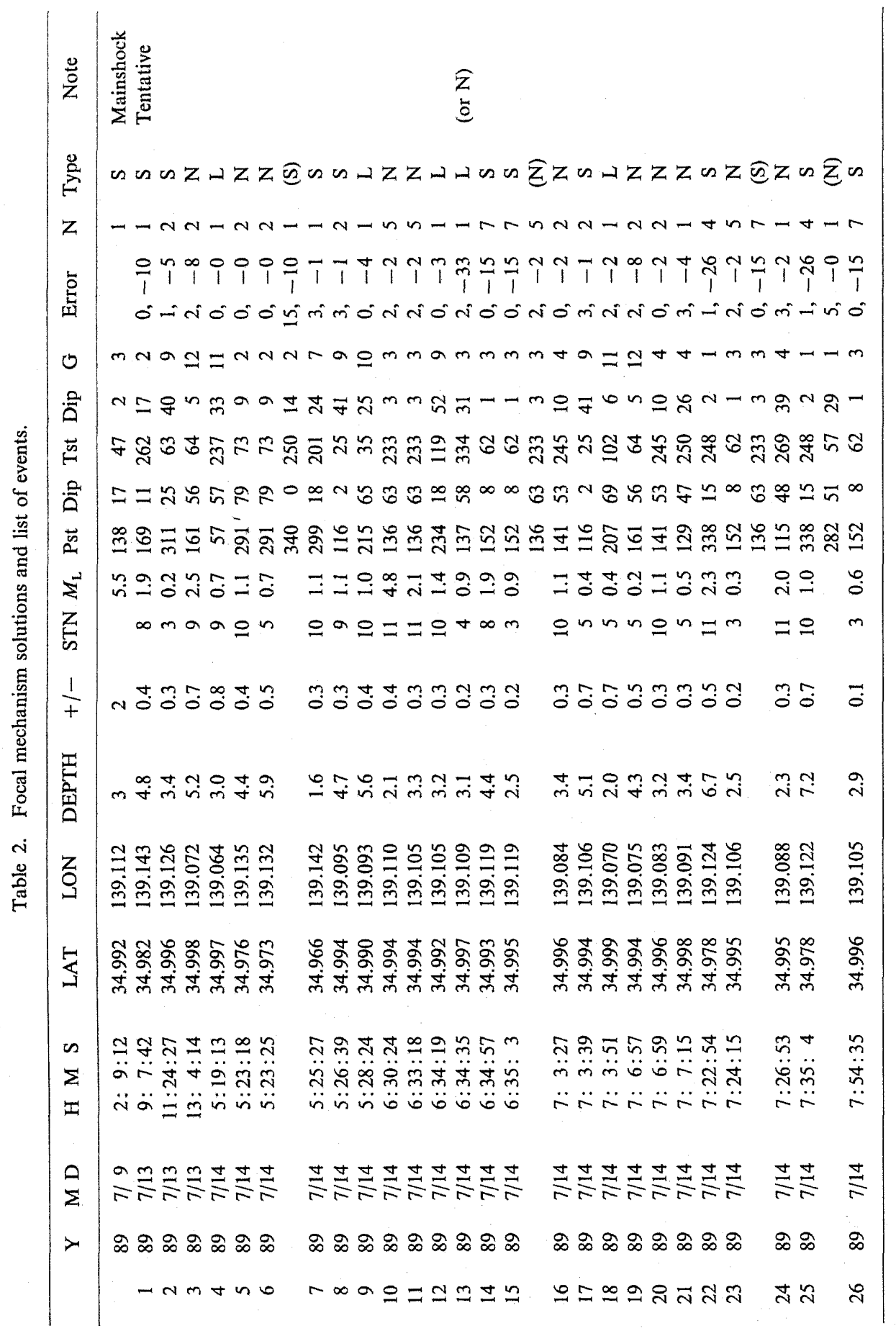




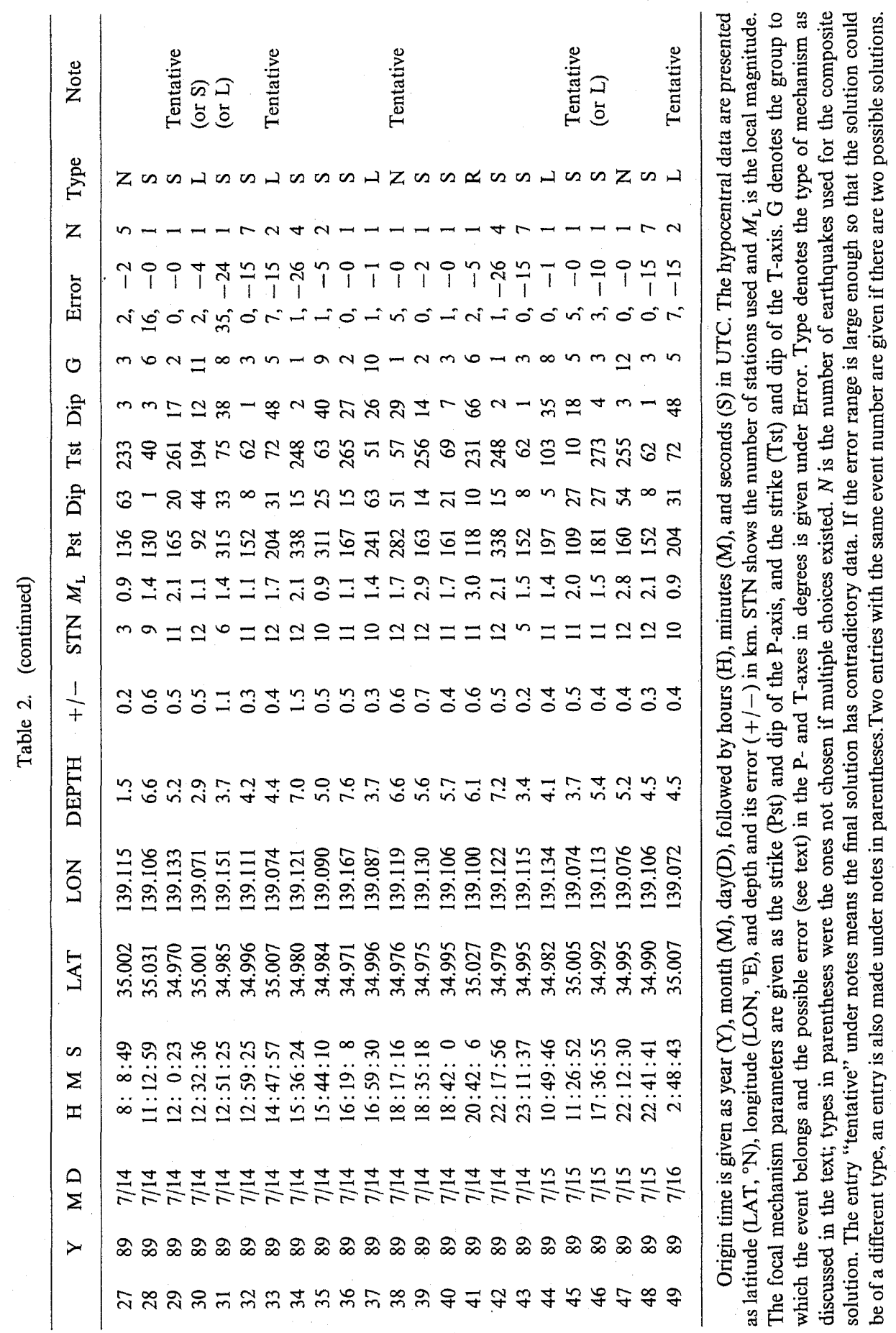

Vol. 41, No. 3, 1993 
sub-stations were deployed (Fig. 1b), one with three components (OSK1) and two with only a north-south component (OSK2, OSK3); however, the north-south component at OSK1 did not work well, reducing it to a two-component sub-station. Transducers used in this study had a natural frequency of $1 \mathrm{~Hz}$ and velocity output. Digital sampling rates varied from 30 to $200 \mathrm{~Hz}$.

The FASTHYPO (Herrmann, 1979) hypocenter location program was utilized in conjunction with a velocity structure based on explosion seismic experiments (Table 1). The shallower part $(0-4 \mathrm{~km})$ of this structure is based on refraction studies by Yoshii et al. (1986), while the deeper part is based on Ikami (1977). A constant $V_{\mathrm{P}} / V_{\mathrm{S}}$ ratio of 1.87 was estimated from Wadati diagrams and used in this study.

An average of 8.9 stations were used to determine a hypocenter. The statistical precision of our epicentral calculations is $+1-0.21 \mathrm{~km}$ in latitude and $+1-0.45 \mathrm{~km}$ in longitude. The mean error in the calculated depths is $+1-0.45 \mathrm{~km}$ and the individual values are shown in Table 2. The precision in origin time is $+1-0.06 \mathrm{~s}$.

The hypocentral distribution determined by our network is generally consistent with that obtained by Kasahara et al. (1991), who used a sonobuoy deployed at the center of the swarm region from July 27 to July 29,1989 , as well as to that recorded by Tohoku University (-1990), who operated a dense array between July 16 and October 31, 1989, after our deployment. The depth distributions from all three deployments show a similar spatial distribution.

The local magnitude, $M_{\mathrm{L}}$, was calculated from the maximum amplitude at OSK using the JMA formula except that an empirically determined value of 0.41 , instead of 1.64, was used as the coefficient for the epicentral distance term. When the records at OSK were saturated, magnitudes were estimated from those calculated by NIED using an empirically determined conversion factor.

The hypocenter $\left(34.992^{\circ} \mathrm{N}, 139.112^{\circ} \mathrm{E}\right)$ and fault plane (strike $\mathrm{N} 86^{\circ} \mathrm{W}$, dip $79^{\circ}$ ) determined by the Japan Meteorological Agency (1990) for the July 9 mainshock were adopted in this paper since they used the largest number of stations. Other epicentral solutions are within 1-2 km (ERI and MRI, 1990; NRCDP, 1990). The fault plane determined by the ERI and MRI (1990) and by NRCDP (1990) have southward dips of about $70^{\circ}$ and $79^{\circ}$, and strikes of about $\mathrm{N} 95^{\circ} \mathrm{E}$ and $\mathrm{N} 102^{\circ} \mathrm{E}$, respectively. These determinations are essentially identical for the purposes of this paper.

\section{Analysis}

The 49 earthquakes used for focal mechanism analysis are shown in Fig. 2 and in Table 2.

The events were divided into 12 groups based on their epicenters and on the polarity of the vertical first motion at OSK (Fig. 2). The spatial extent of each group was less than $4.4 \mathrm{~km}$. In the absence of any notable structural features (Research Group for Active Faults of Japan, 1991), we assume that events that occurred in close proximity to each other resulted from the same stress field (e.g., Aki, 1966; Pechmann and Kanamori, 1982).

P-wave first motion data were primarily used to determine a composite focal mechanism for each group. S-wave polarizations were estimated for a few stations 


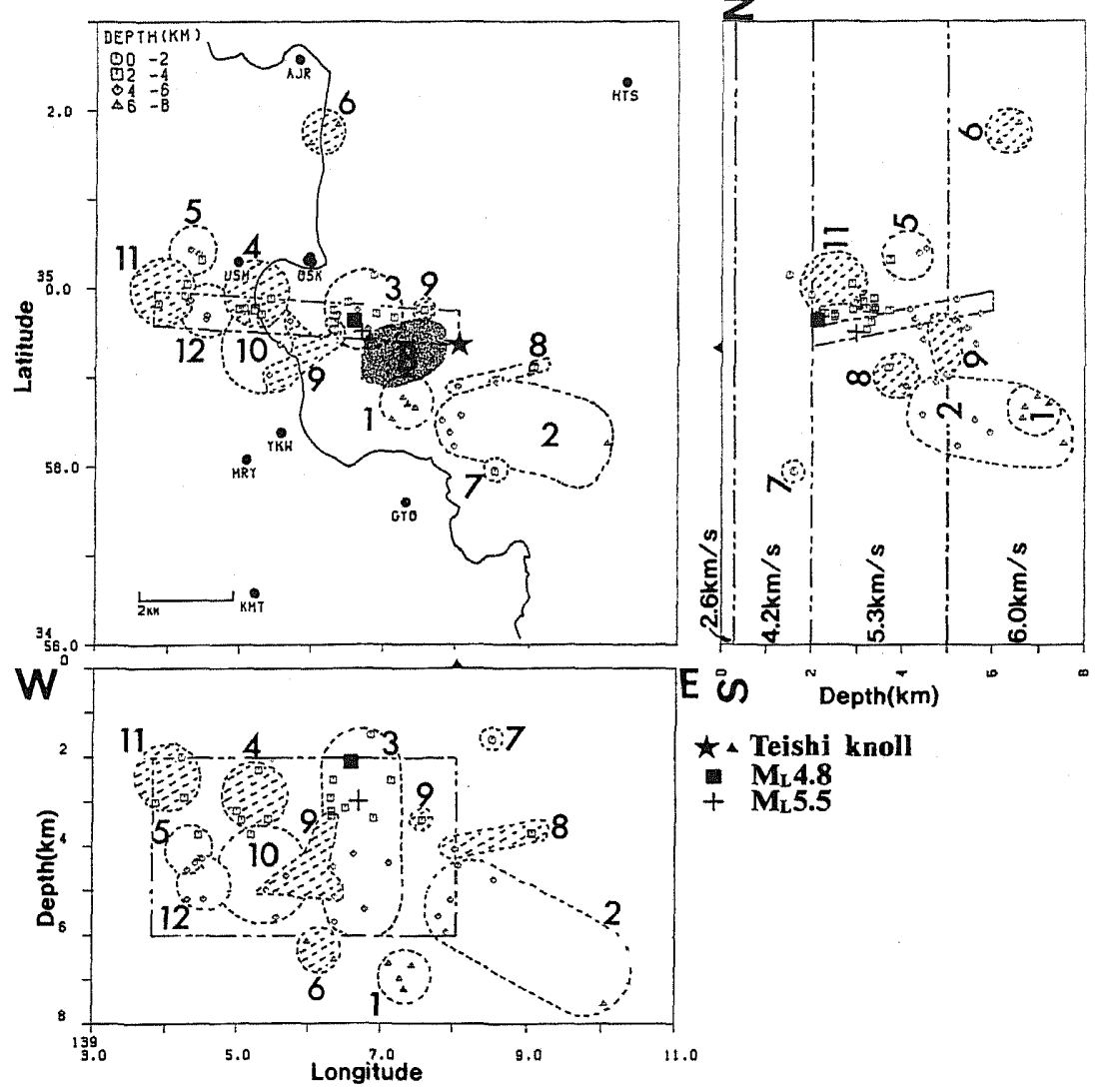

Fig. 2. Hypocentral distribution and source groups of earthquakes used in this study. Plan and north-south (not all groups identified) and east-west cross sectional views of the earthquakes used in this study are shown; focal depth is shown by the different symbols. The mainshock $\left(M_{\mathrm{L}} 5.5\right)$ is shown by a cross, the $M_{\mathrm{L}} 4.8$ aftershock by a solid square. The numbers denote the group numbers assigned. Solid dots represent seismic stations. The shaded groups are those from which compressional first motions were observed at OSK; all other events had dilatational first motions at OSK. The stippled area labeled $B$ denotes a cluster that occurred subsequent to our study period and located by Tohoku University (1990). The rectangle denotes the mainshock fault area.

(including OSK and KMT) when the S-wave could be clearly identified and its emergence angle was less than critical and were used to fine tune the final mechanism (Honda, 1962). P-wave first motion and S-wave polarization data were plotted on an equal area, upper hemisphere projection of the focal sphere (Fig. 3).

First, the solution which fit the most data was identified; except for group 7, which had only one event, no solution satisfied all of the events belonging to any group simultaneously. Then, events whose data clearly contradicted the initial solutions were 

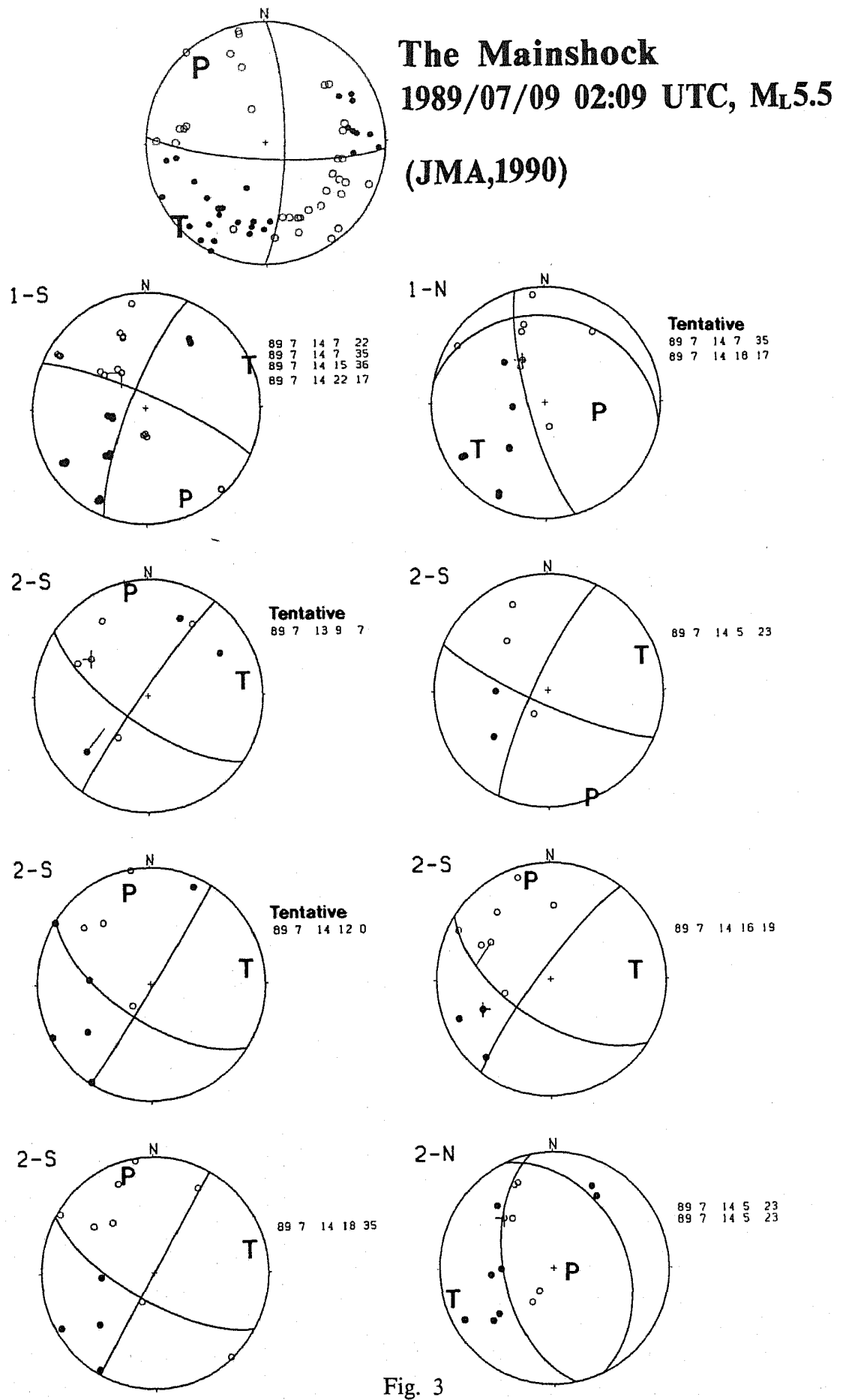

J. Phys. Earth 

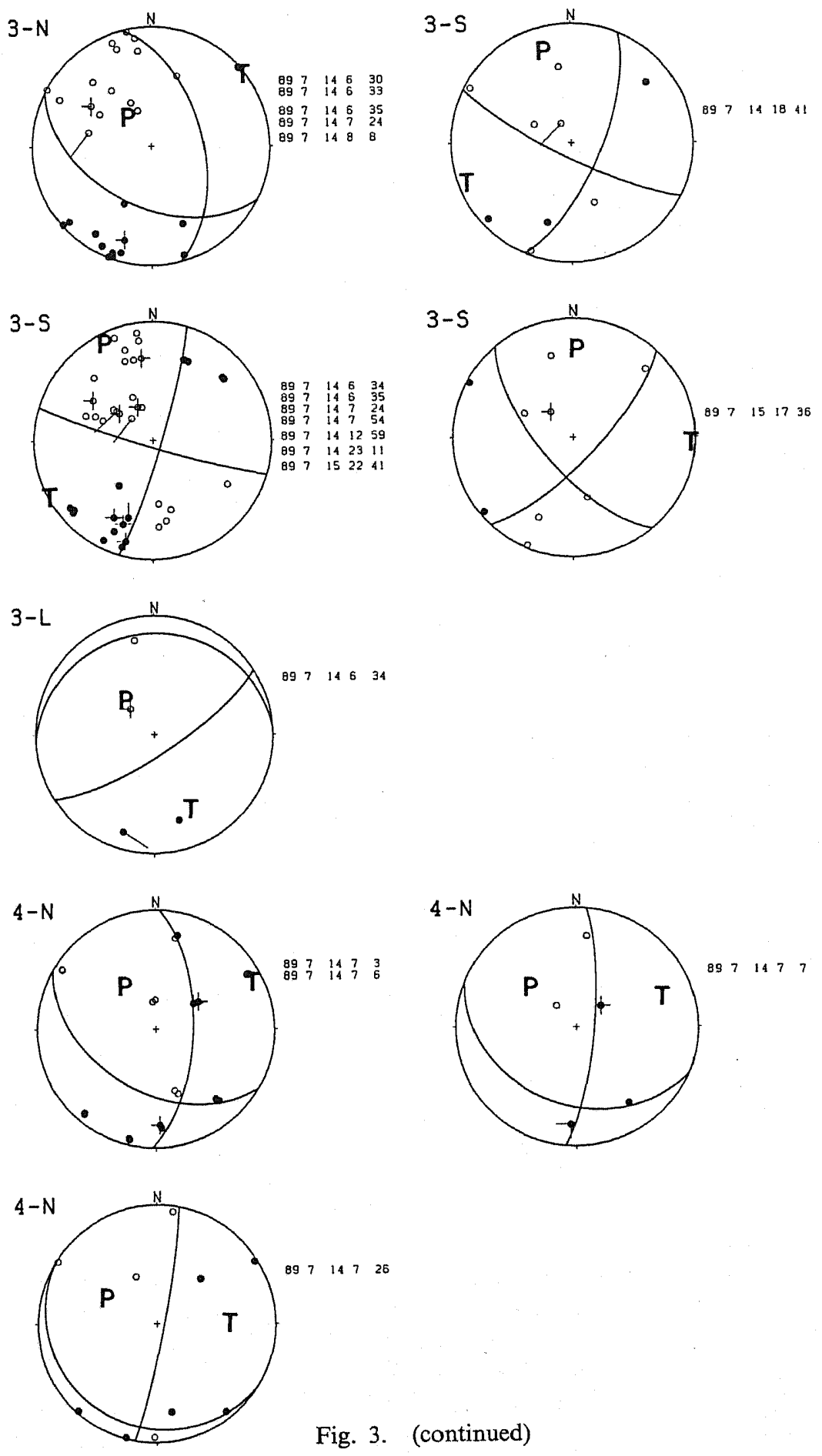

Vol. 41, No. 3, 1993 

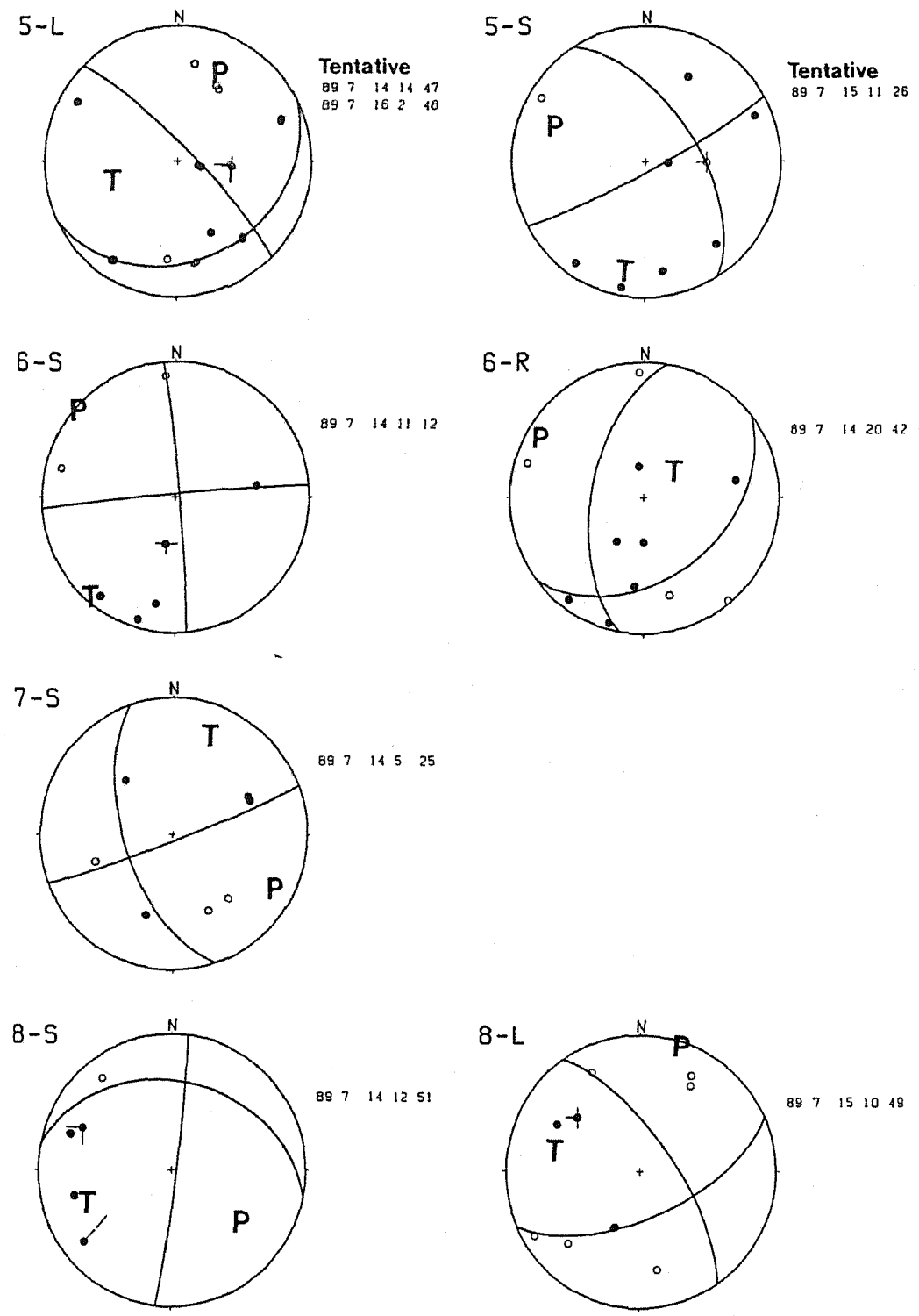

Fig. 3. (continued)

removed and placed into subgroups. Finally, the mean possible orientation of the nodal planes were adopted for each group. Subgroups were reanalyzed in the same manner. The estimated S-wave polarizations were used in the final step to confirm solutions obtained only by the P-wave first motions. The final solutions are shown in Fig. 3 and presented in Table 2. The solutions are classified into types as discussed later.

In some cases, there were clearly two different solutions within a group (e.g., 3-N 

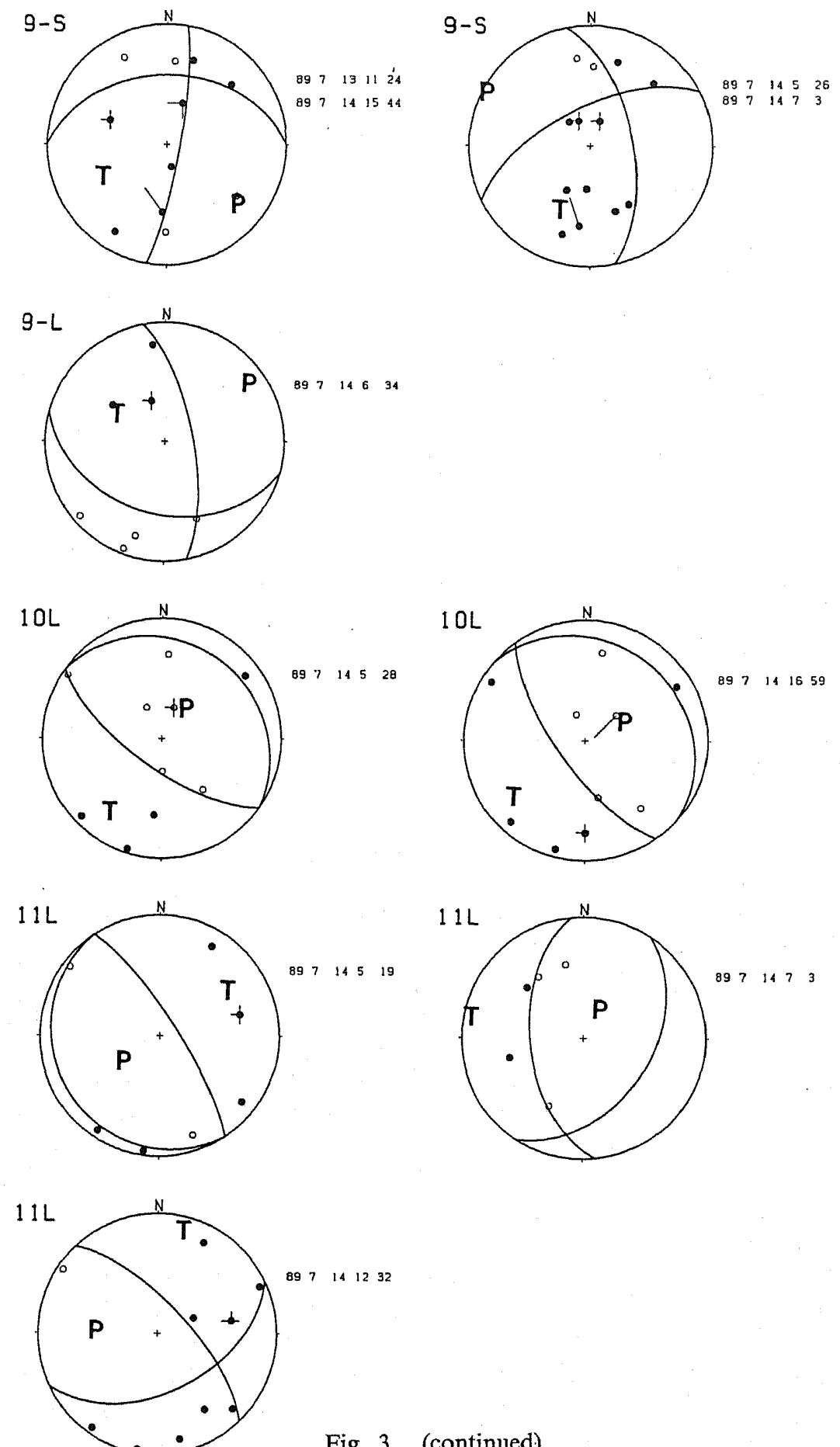

Fig. 3. (continued)

Vol. 41, No. 3, 1993 

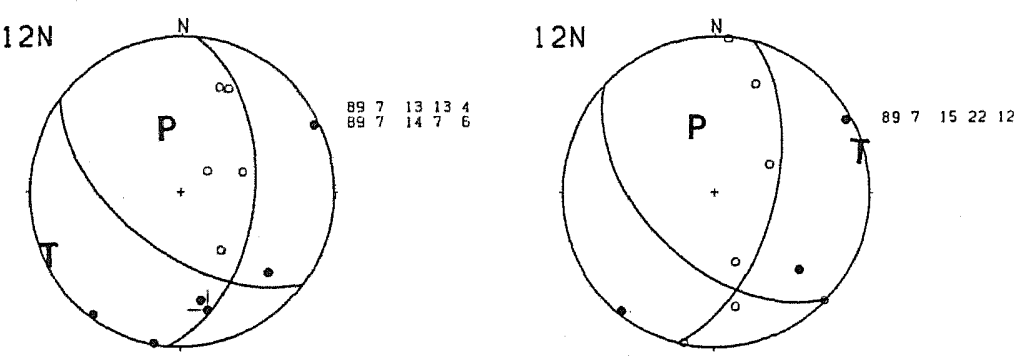

Fig. 3. Composite focal mechanism solutions of the mainshock and aftershocks shown as equal area upper-hemisphere projections of the focal sphere. Solid circles are compressions, open circles are dilatations. "P" and "T" denote the locations of the $\mathrm{P}$ - and $\mathrm{T}$-axes, respectively. The + denotes the center of the projection. Estimated S-wave polarization data are shown by the long bars. S-wave polarizations estimated from two saturated components are shown by the two short bars which indicate the range of possible polarizations. Stations which recorded S-waves but for which the first break could only be identified clearly on one component are shown by three bars. The group number and event type are shown to the upper left of each mechanism, while the events used to form the composite are shown to the right. The label 'tentative' indicates that there are some contradictory first motions.

and 3-S; Fig. 3). This is probably because the spatial extent of some of the groups was too large or because some preexisting planes of weakness may have existed. This phenomenon is discussed later.

The final solutions have no major contradictions in either P-wave first motions or S-wave polarizations. Solutions with contradictory $\mathrm{P}$-wave first motion data are called 'tentative.' However, the error in these 'tentative' solutions is small since the contradictory data points are near the nodal planes.

As noted above, S-wave first motions were used to constrain the final focal mechanism solutions. In three cases, the S-wave data are critical in determining a solution (group 6-S, which could be equivalent to 6-R without the S-wave data; 3-L, which could be equivalent to $3-\mathrm{N}$; and $8-\mathrm{S}$ which could be equivalent to $8-\mathrm{L}$ ).

$\mathrm{S}$-wave polarizations can be approximated from the horizontal first motion if the incidence angle is less than the critical angle $\left(32^{\circ}\right)$ and the P-SV conversion at the surface is ignored (c.f., Ma and Kanamori, 1991). For most of our data, the epicentral distances are small enough to meet these conditions. In addition, although our constraint on S-wave polarizations are poor in some cases, they are sufficient to resolve that these mechanisms are different.

Figure 4 shows two representative waveforms demonstrating the quality of the S-arrivals; one of them has clear S-waves while the other has some ambiguity in identifying the S-wave arrival on the east-west component. In Fig. 3, we show the unambiguous data by one long bar and the less certain arrivals by two or three short bars. The two bars represent the possible range of the estimated polarization angle obtained from two saturated horizontal components, while the three bars represent 


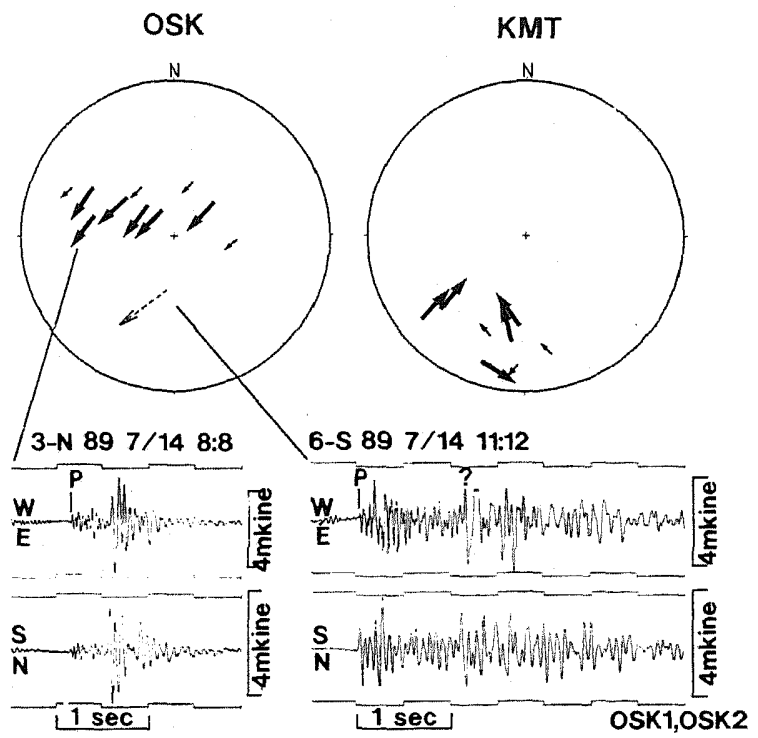

Fig. 4. Composite S-wave polarizations at the source observed at stations OSK and KMT. S-wave polarizations from Fig. 3 are plotted on an upper-hemisphere projection of the source. The polarization directions are plotted at the emergence point from the focal sphere. The bold arrows represent good two-component data, while the smaller arrows show estimated polarizations from two saturated components. Sample records of S-wave data from OSK are shown below. The event on the left shows good S-wave data, while the event on the right shows poorer quality data where the time of the S-arrival is more ambiguous.

observations from stations where the first break of the S-wave is observed clearly on only one component with the central bar points in the direction of the first break.

We note that $\mathrm{S}$-wave polarizations observed at the surface can be affected by topography near the station, lateral heterogeneities beneath the station, and possible anisotropy along the ray-path between the source and the receiver (e.g., Kaneshima et al., 1987; Kaneshima, 1990; Crampin and Lovell, 1991). The S-wave polarizations used in this study are also shown in Fig. 4, plotted as emergence angle from the focal sphere. The data from OSK appear aligned while those from KMT appear random. The azimuth of alignment at OSK, however, is about $90^{\circ}$ from the estimated direction of tectonic compression (N45-55 W; Tsukahara and Kobayashi, 1991; Ukawa, 1991), thus tectonic stress does not appear to be the cause.

Even if some local stresses or topography played a part in aligning the polarizations at OSK, it is unlikely to affect the polarization vectors so much that the S-wave polarizations could not be used to discriminate focal mechanisms. This can be demonstrated by a simulation of the S-wave arrival as follows: Assume that the incident $\mathrm{S}$-wave consists of one cycle of a sine wave with unit amplitude. Then, the waveforms of a wave passing through an isotropic medium can be expressed as Eqs. (1) and (2)

Vol. 41 , No. 3,1993 


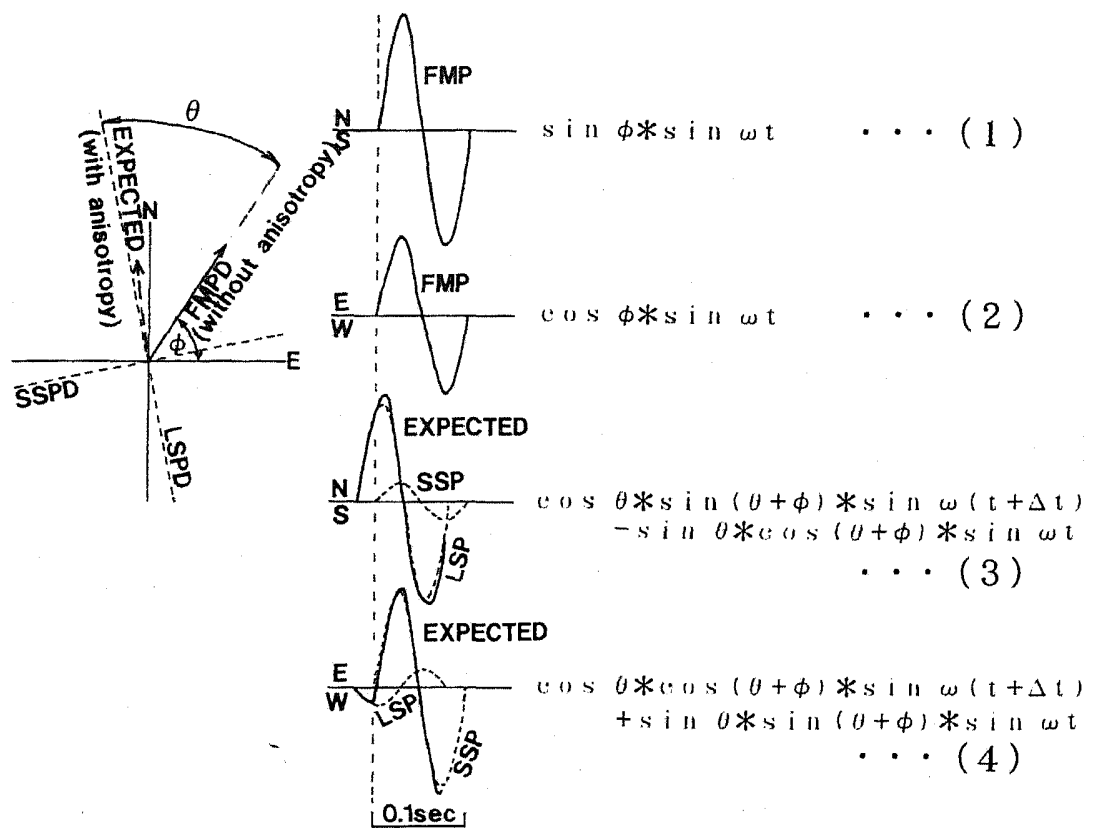

Fig. 5. Schematic explanation of the simulation to estimate effects of S-wave anisotropy. We assume that incidence S-wave is one cycle of sine curve, that the S-wave polarization is oriented $\phi$ counterclockwise from the east in an isotropic medium, that the S-wave first motion has a pulse width of $0.05 \mathrm{~s}$, and that anisotropy results in a $0.02 \mathrm{~s}$ travel-time difference $(\Delta t)$ between the leading and secondary S-waves. The top two waveform figures assume no anisotropy, while the lower two waveforms show the effects of anisotropy. In the figure, FMP denotes the focal mechanism polarization waveform, LSP the leading shear wave polarization, SSP the secondary shear wave polarization, and EXPECTED, the sum of LSP and SSP, is the waveform expected to be observed as a result of anisotropy. The figure at the left shows the polarization directions inferred from these waveforms. LSPD is the leading shear wave polarization direction, SSPD is the secondary shear wave polarization direction, FMPD is the focal mechanism polarization direction, and EXPECTED is the polarization observed from the bottom two waveforms. The equations at the right describe the FMP and the EXPECTED waveforms where $\theta$ and $\omega$ are the angle between the LSPD and the FMPD, and the angular frequency of the S-wave pulse respectively.

in Fig. 5, and those passing through an anisotropic medium by formulas (3) and (4), where $\phi, \theta, \Delta t, \omega$, and $t$ denote the $\mathrm{S}$-wave polarization direction, the angle between the leading S-wave polarization direction (LSPD) and the focal mechanism polarization direction (FMPD), the time difference between the leading and secondary S-waves, the angular frequency of the $S$ wave, and time, respectively (Fig. 5). We calculated $\lambda$, the difference in angle between the FMPD and the expected polarization angle. For this 
calculation, $\theta$ was varied at $1^{\circ}$ increments and $\phi$ chosen so that $\theta+\phi$, the LSPD, was constant as observed. Finally, when the calculated expected polarization angle fell into the range $\mathrm{N} 141-145^{\circ} \mathrm{W}$, the observed range, we determined the value of $\lambda$. We used a sampling rated of $100 \mathrm{~Hz}$, a $\Delta t$ of $0.02 \mathrm{~s}$, and pulse width of $0.05 \mathrm{~s}$. Under these conditions, our calculations indicate that the maximum possible difference in the polarization angle between strongly isotropic and anisotropic materials is $28^{\circ}$. Thus, data represented by one bar in Fig. 3 probably represent polarization at the source. However, data shown by two or three bars (i.e., saturated data on two components or data with ambiguity on one component) may be significantly less reliable. In either event, they are sufficient to discriminate between mechanism types.

The P-axis of the mainshock $\left(\mathrm{N} 138^{\circ} \mathrm{E}\right)$ is in the direction of regional tectonic compression $\left(\mathrm{N} 125-135^{\circ} \mathrm{E}\right)$, and the mainshock fault plane $\left(\mathrm{N} 86^{\circ} \mathrm{W}\right)$ is oriented $31-41^{\circ}$ from the regional compression axis. These indicate that the mainshock was generated under the regional tectonic stress field (e.g., Zoback et al., 1987). Thus, the focal mechanism solutions were next divided first into those events with $\mathrm{P}$ - and T-axes within $45^{\circ}$ of those of the mainshock ('aftershock' type), and those with P-and T-axes which

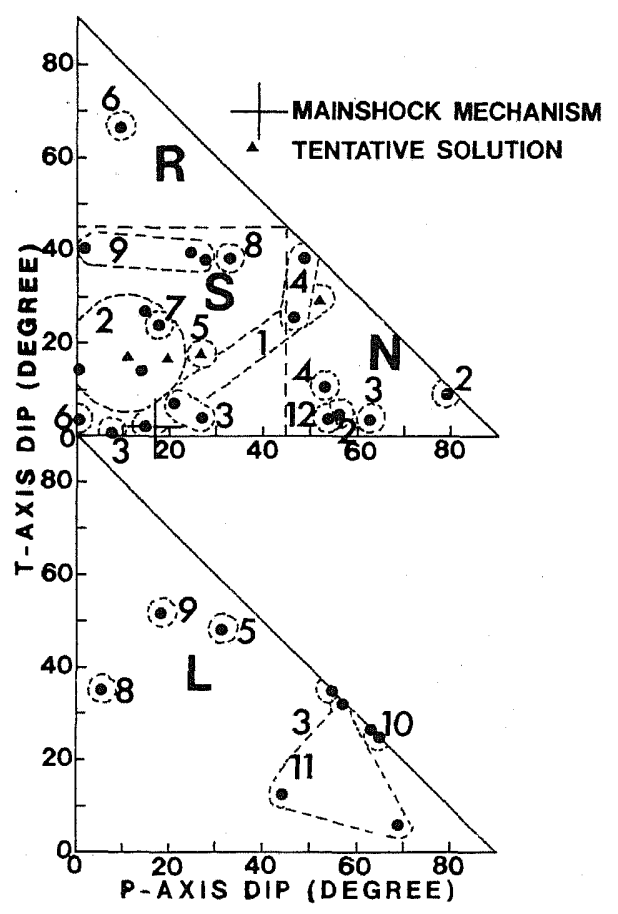

Fig. 6. Variation and classification of the focal mechanism solutions. The upper triangle shows 'aftershock'-type events and their sub-classification into $\mathrm{N}$ - (normal), R- (reverse), and S- (strike-slip) types. The fields are delineated by the straight dashed lines. Curved dashed lines separate the individual groups. The lower triangle shows L-type (local stress field) events (see text). Solid circles show individual events, with the triangles denoting 'tentative' solutions.

Vol. 41, No. 3, 1993 


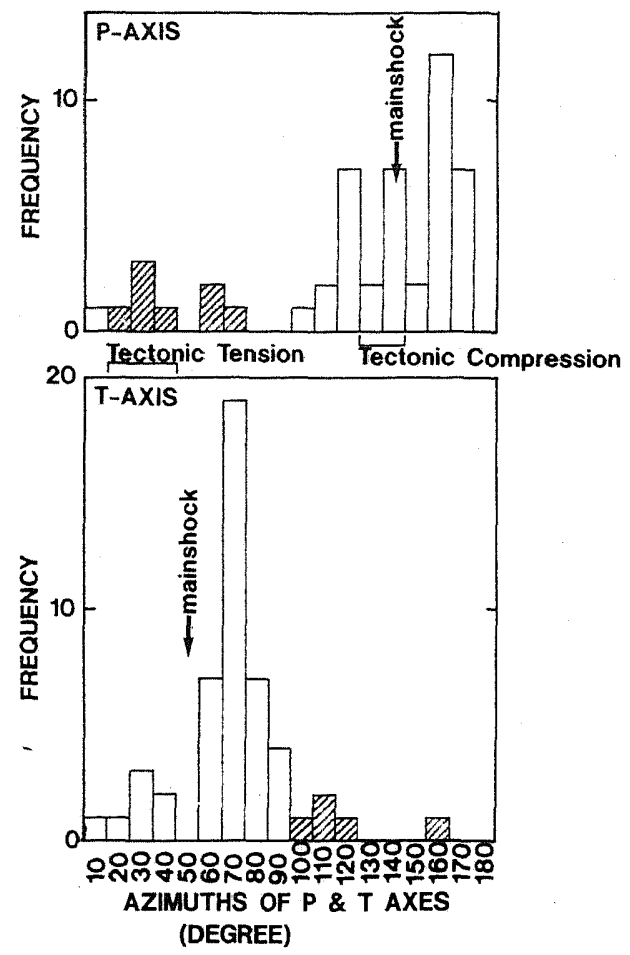

Fig. 7. Azimuthal distribution of $\mathrm{P}_{-}$and $\mathrm{T}$-axes. Histogram showing the distribution of $\mathrm{P}$ - and $\mathrm{T}$-axes in $10^{\circ}$ increments. The arrows indicate the values for the mainshock. Shaded events are those of the L-type. The regional tectonic compression and tension directions are noted by brackets between the graphs.

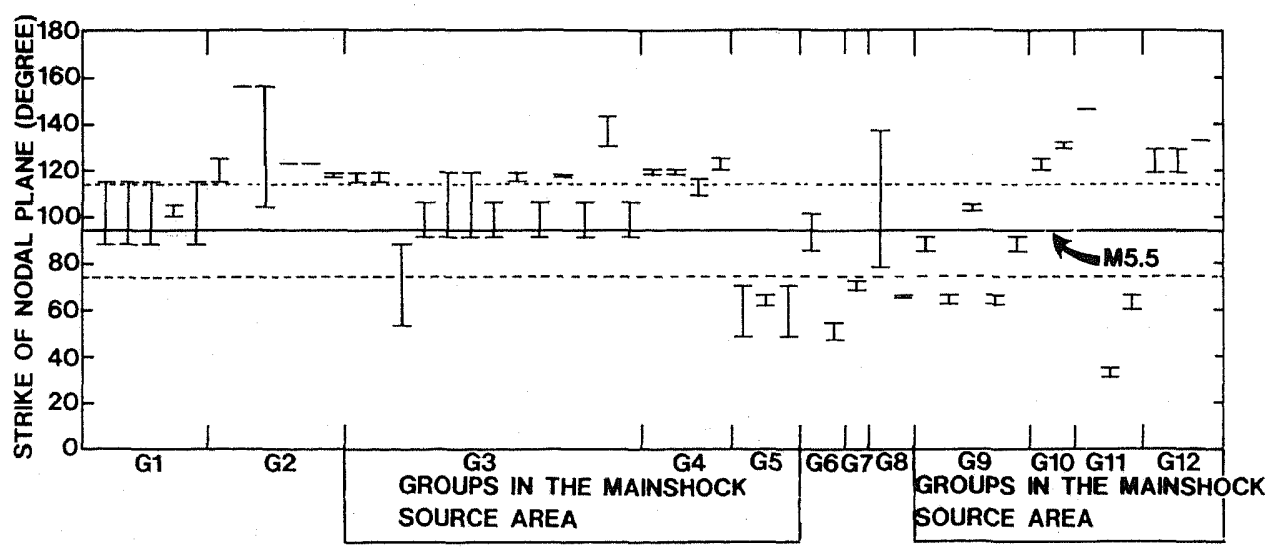

Fig. 8. Comparison of nodal plane strikes. The strikes of the nodal plane closest to the mainshock fault plane strike $\left(\mathrm{N} 94^{\circ} \mathrm{E}\right)$, with errors, are plotted by group. The solid line shows the strike of the fault plane of the mainshock. The dashed lines show a variation of $+1-20^{\circ}$. 
deviated more than $45^{\circ}$.

We propose that the latter events were probably generated under a local stress field and/or by failure along preexisting planes of weakness (e.g., McKenzie, 1969) and we call them L-(local stress field) type events. The 'aftershock'-type events are further subdivided into normal faulting (N-type), reverse faulting (R-type), and strike-slip (S-type) type events. The $\mathrm{N}$-type mechanisms are defined as those which have $\mathrm{P}$-axes that dip more than $45^{\circ}$, the R-type as those with $\mathrm{T}$-axes that dip more than $45^{\circ}$, and the S-type as those with P-and T-axes that dip less than $45^{\circ}$. The distribution of events according to this classification is shown in Figs. 6 and 7. No apparent pattern is observable.from Fig. 6.

The error in determining the focal mechanism solutions is estimated by the possible variation of the nodal plane azimuths. For the 'tentative' solutions, the error is defined as the rotation angle needed to move contradictory data to the proper side of the nodal plane. The errors are shown in Table 2 and Fig. 8.

\section{Analysis of Focal Mechanism Solutions}

The focal mechanism solutions were examined according to their spatial, temporal, and statistical aspects. The spatial distribution of the focal mechanism solutions in map and cross-sectional views is presented in Fig. 9, where the symbols denote the focal mechanism types. In the map view of Fig. 9, regions where the surficial area-strain field should have been reduced as a result of the mainshock, calculated using the method of Sato and Matsu'ura (1974), are stippled; the coarse stippling shows the region where maximum surficial area-strain reduction is expected.

Figure 9 shows that S-type and $\mathrm{N}$-type events are predominant in the source area of the mainshock. The N-type events occurred in the shallower and western part, while the S-type events occurred in the deeper and eastern part. These features are also seen even if we consider only events larger than $M_{\mathrm{L}} 2.0$ to compare our focal mechanisms with those of other studies. Although the L-type events occurred throughout the region, they appear to concentrate at the edges of the mainshock source area, especially where the surficial area-strain has been reduced the most. We propose that the L-type events were caused the development of a local irregularity in the redistributed stress pattern and/or the existence of some mechanically weak preexisting fractures (e.g., Matsumura et al., 1991). However, we recognize that the L-type events may be due simply to natural variations associated with low-magnitude seismicity because of their comparatively small magnitude $\left(M_{\mathrm{L}}<2\right)$. We discuss this further below.

Previously obtained focal mechanism solutions for events that occurred in and around the study area in the past show that they were primarily strike-slip (S-type) and had P- and T-axis azimuths of WNW-ESE and NNE-SSW, respectively, during 1979-1983 based on events of $M_{\mathrm{L}} \geq 4$ (Mochizuki et al., 1985), and northwest-southeast and northeast-southwest, respectively, during 1981-1988 based on events of $M_{\mathrm{L}} 2-4$ (Ukawa, 1991). Thus, between 1979 and 1988, N-type, R-type, and L-type events are thought to have been relatively rare.

Based on $76 M_{\mathrm{L}}>3$ events studied using the NIED network from July 4 to July 12,1989 , strike-slip events were found to be dominant in the study area (Matsumura

Vol. 41, No. 3, 1993 


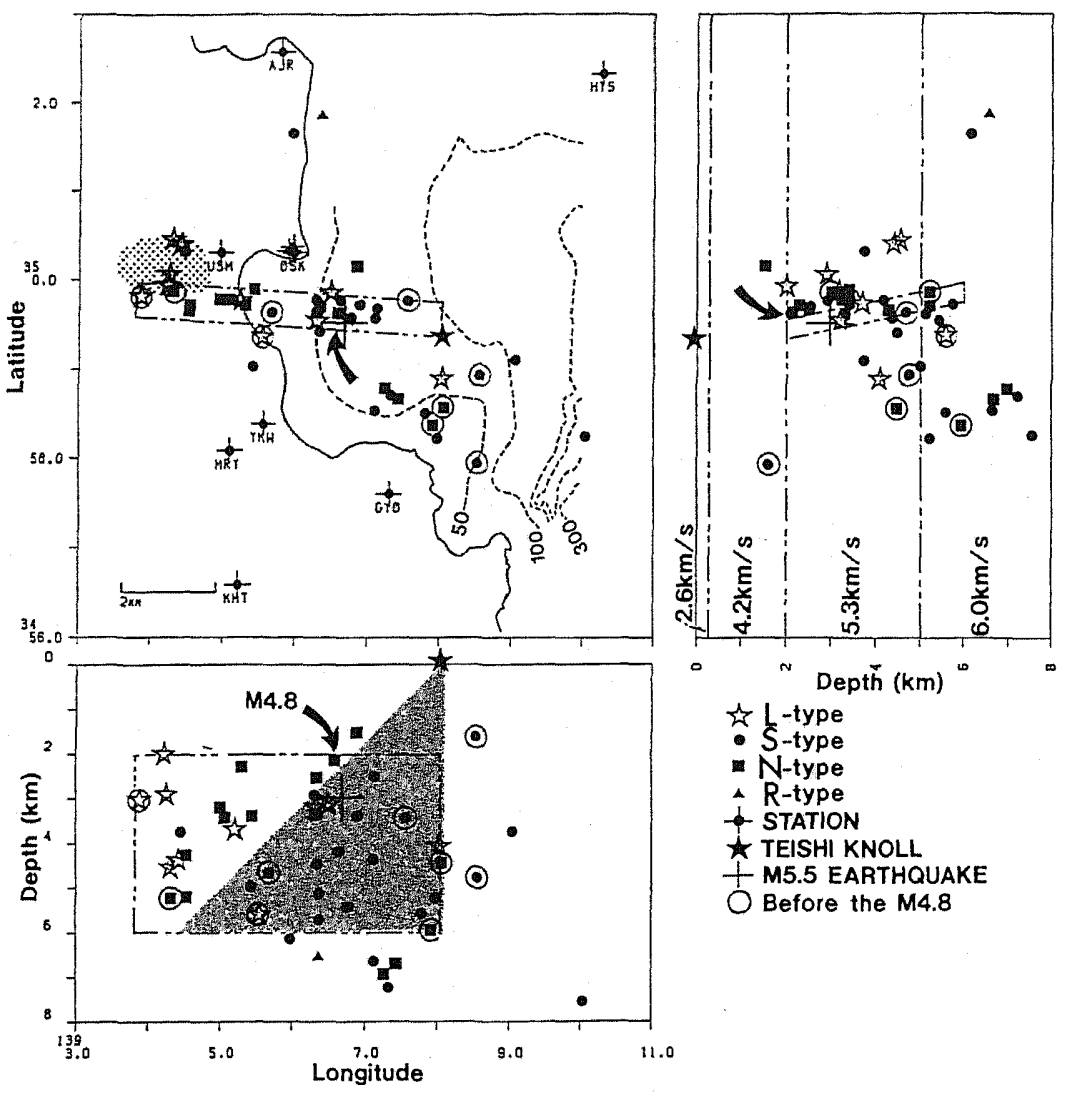

Fig. 9. Spatial distribution of focal mechanism types. Plan and north-south and east-west cross sectional views of the mainshock source area (dash double-dot line) showing the spatial distribution of focal mechanisms. The stippled areas on the map view show regions where the surficial area-strain is expected to be reduced; the coarse stippling shows the region of maximum area-strain reduction. The stippled area in the east-west cross section denotes the area intruded by magma prior to the study period. The mainshock is shown by a cross, stations as solid circles with crosses, the $M_{\mathrm{L}} 4.8$ aftershock by the arrow, and Teishi knoll by a star. Different symbols are used for the different event types. Events which occurred prior to the $M_{\mathrm{L}} 4.8$ aftershock are circled. In the map view, broken lines show bathymetric contours ( $50 \mathrm{~m}$ interval) adapted from the Maritime Safety Agency (1990).

et al., 1991) immediately prior to our study period. However, they also reported several unusual normal faulting solutions with northwest-southeast striking tensional axes (L-type events). These L-type events, which occurred before the mainshock, were located in the area covered by our groups $1,2,7$, and 8 (see Fig. 2). They further reported that such irregular solutions deviated from the average trend of stress trajectories.

Tohoku University (1990) determined 65 focal mechanism solutions $\left(M_{\mathrm{L}}\right.$ is $2-3$, 
estimated from JMA observations) for the period July 16 to Oct. 31,1989 , immediately after our study period. These events were mainly of the S-type. $15 \%$ of those events, however, located in the area including our groups $1,2,4,5,7,8,9,10$, and 12 , were of the R-type. Specifically, the area including our groups $4,5,9,10$, and 12 had a total of 39 focal mechanism determinations, which included about 30 events of the S-type, 6 events of the R-type, several of the L-type, and 1 event of the N-type.

Thus, we can summarize the temporal variations as follows. First, S-type events were dominant during the period from July 4 to Oct. 31 , as they had been during 1979-1988. N-type events occurred in a fixed area during our study period and into the period:afterwards, but, their frequency decreased after our study period. L-type events occurred even before the mainshock and had stress axes that deviated from the average trend. Finally, R-type events occurred after our study period in an area where no R-type had previously been observed.

The number of events used in this study is too small to make rigorous statistical interpretations. However, several tendencies are apparent which are reinforced by data obtained by studies covering the time period preceding and following our study (Matsumura et al., 1991; Tohoku University, 1990). Figure 7 shows that the azimuths of $\mathrm{T}$-axes cluster in a narrower band than those of $\mathrm{P}$-axes. This means either that the azimuth of the minimum principal stress $\left(\sigma_{3}\right)$ axis was more stable than that of the maximum principal stress $\left(\sigma_{1}\right)$ during the study period in the study area, or that the tensor aspect ratio $\left(\left[\sigma_{1}-\sigma_{2}\right] /\left[\sigma_{1}-\sigma_{3}\right]\right.$, where $\sigma_{i}$ are the magnitudes of the principal stresses, $\sigma_{1} \geq \sigma_{2} \geq \sigma_{3}$, Celerier, 1988) was small. Although events were classified as 'aftershock'-type because their P- and T-axes azimuths were similar to those of the mainshock, the azimuths of the P-and T-axes vary somewhat (about $20^{\circ}$ ) from those of the mainshock. From Fig. 8, it can also be seen that the azimuths of nodal planes of the events which occurred in the mainshock source area are often $20-30^{\circ}$ different from that of the mainshock.

\section{Discussion}

Generally, areas where normal faulting occur are thought to be in a tensional stress field. Matsumura et al. (1991) pointed out that the mixture of various types of mechanisms, particularly normal faults associated with magma intrusion, often appear in volcanic regions (e.g., Yamaoka et al., 1988). Thus, the concentration of N-type events in the shallower and western part of the mainshock source area indicates that those regions were in a tensional stress field, probably resulting from magma penetration related to the submarine eruption.

Tohoku University (1990) reported that during the period July 16-October 31 , 1989, events near our groups 1, 2, 3, 7, and 8 (Fig. 2.; their clusters B and C) reached a depth within $1 \mathrm{~km}$ of the sea bottom. Tohoku University (1990) also proposed that their cluster B (near our group 3 ) had a close affinity to the magma migration since the cluster was located right under Teishi knoll and was distributed downward in a long and narrow area. On the other hand, by comparing the observed and theoretical crustal movement data, Okada and Yamamoto (1991) suggested that the collision of the mainshock shear fault with the magma-induced tensile fault resulted in the entry of

Vol. 41, No. 3, 1993 
magma into the soft sedimentary layers at the sea bottom, resulting in a submarine eruption which formed a sill and Teishi knoll. They estimated that the tensile fault was located in the area of our groups 1,2,7, and 8. The development of $\mathrm{N}$ - and L-type events in the southeastern part of the study area agree with their model that magma intruded there and caused tensile stresses and that some tensile stress persisted even after the submarine eruption and the occurrence of the largest $\left(M_{\mathrm{L}} 4.8\right)$ aftershock. After the submarine eruption, however, the tensile stress field enlarged to include the shallower and western part of the mainshock source area while it decreased in its deeper and eastern part. Subsequently, the tensile stress field disappeared in the southeastern part of the study area (the area of groups 1,2, 7, and 8) since only one L-type and no $\mathrm{N}$-type events, but $15 \mathrm{~S}$ - and 2 R-type events, were reported by Tohoku University (1990) after the end our study period.

In contrast, group 3 had $\mathrm{N}$-type events at $1-3 \mathrm{~km}$ depth, including the largest aftershock, and they occurred after the submarine eruption. Thus, there is a suggestion that there was magma penetration which resulted in tensile stress in that region even after the submarine eruption. The region had only two events for which mechanism solutions (both S-type) were determined by Tohoku University (1990), so we cannot determine if the tensile stress continued after our study period. However, we can say that any local stress that existed there diminished rapidly, because the seismic activity of the group 3 region (including a part of cluster B of Tohoku University, 1990) reportedly diminished more rapidly than the other clusters.

The postulated tensile stress in the shallower and western part of the mainshock source area may also have been caused by magma penetration. The side view of Fig. 9 shows the estimated region of magma penetration for the eruption (stippled triangular area), assuming that once the magma penetrated, very little tensile stress existed in the penetrated area. Thus, combining the regions thought to have been penetrated by magma before and after the eruption, the region mechanically affected by magma intrusion is approximately $90 \%$ of the mainshock source area and reached a depth of $1.5 \mathrm{~km}$ near station OSK. During the four hours immediately after the occurrence of the $M_{\mathrm{L}} 4.8$ aftershock, eleven events were observed at OSK with S-P times less than $0.5 \mathrm{~s}$ and dilatational P-wave first motions (Fig. 10; the $M_{\mathrm{L}} 4.8$ aftershock also had a dilatational first motion at OSK). This suggests that these events occurred at a shallower depth than the $M_{\mathrm{L}} 4.8$ aftershock but were of the same $\mathrm{N}$-type as the $M_{\mathrm{L}} 4.8$ event. Thus, it was after the $M_{\mathrm{L}} 4.8$ aftershock that the postulated tensile stress field induced by the magma penetration, reached a depth of $1.5 \mathrm{~km}$ around OSK. On the other hand, the deeper and eastern area of the mainshock source area was not in the tensile stress field during the study period, because magma penetration had already occurred; thus primarily S-type events were observed. This phenomenon suggests that the magma penetrated the deeper and eastern (stippled area in the side view in Fig. 9) and stayed there during the study period.

The concentration of $\mathrm{N}$ - and S-type events and the decrease in $\mathrm{N}$-type events after the study period indicate that the tensional field existed in the shallower and western part of the mainshock source area during our observation period, but diminished rapidly afterwards.

The concentration of L-type events in the area where the surficial area-strain was 


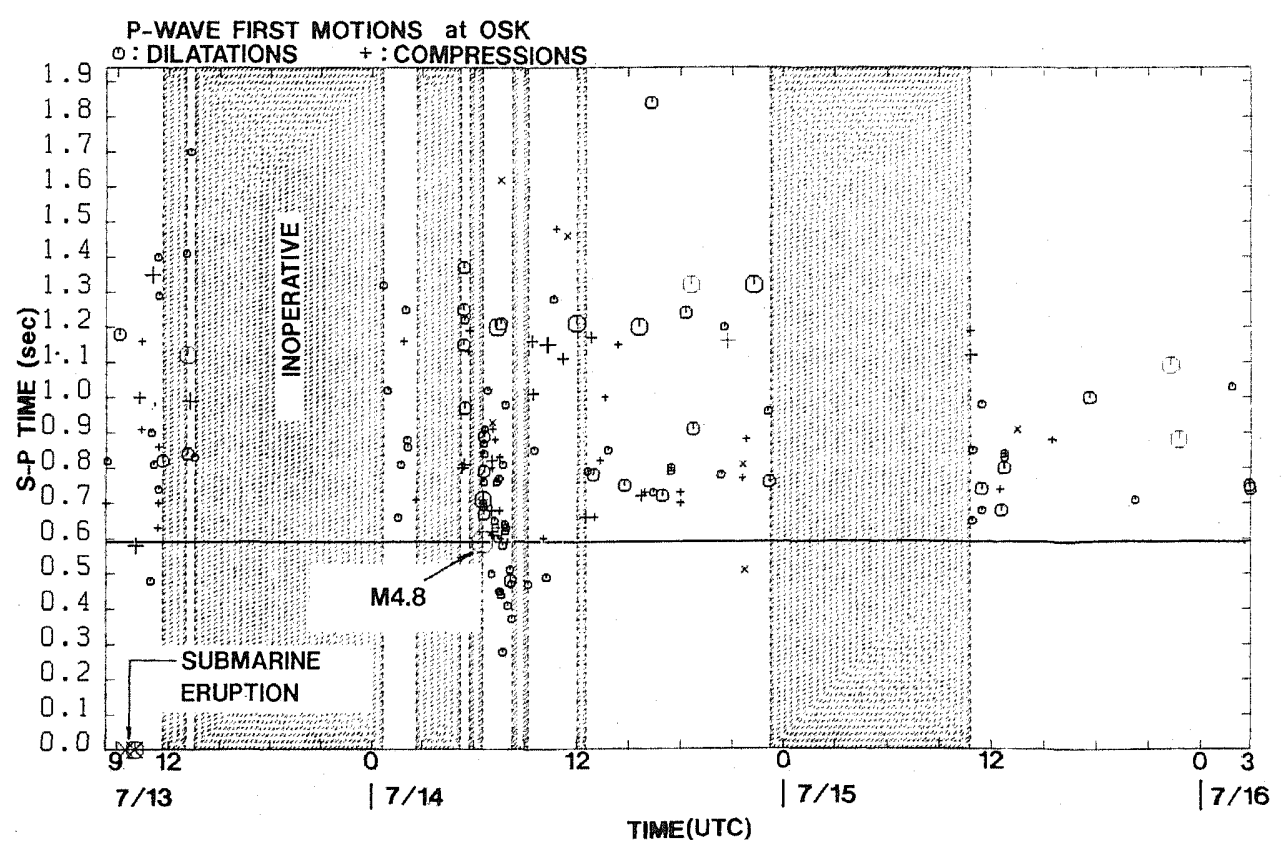

Fig. 10. Time dependence of S-P times and first motions observed at OSK. Circles show dilatational first motions and crosses show compressional first motions. An $\times$ denotes an ambiguous first motion. Lighter symbols are used for events whose S-phase could not clearly be identified and the S-P time deduced from the hypocentral solution. The $M_{\mathrm{L}} 4.8$ aftershock is identified by an arrow. The shaded areas denote times during which the network was inoperative. Events with no S-phases are plotted along the $0.0 \mathrm{~s}$ axis.

reduced the most is related to the redistribution of local stresses. Odaka et al. (1991) reported from numerical computations that an increase in the fracture stress (the resultant stress of Rybicki et al., 1985, which is the sum of the shear stress and a certain portion of normal stress, and indicates the effective stress which contributes to generating fracture) occurs on areas of vertical strike-slip faults where the medium is subject to dilation. This indicates that the aftershock activity concentrates in the area where the surficial area-strain is reduced, and the azimuths of the $\mathrm{P}$ - and T-axes of these aftershocks become nearly equal to that of the mainshock. Thus, the area where the surficial area-strain reduced most is expected to have a special stress field, but it does not explain why L-type events occur there.

Yamakawa et al. (1972) reviewed the aftershocks of the $M_{\mathrm{L}} 7.9$ Tokachi-oki earthquake of 1968. The largest aftershock of this earthquake had a magnitude of 7.5 and its $\mathrm{P}$ - and $\mathrm{T}$-axes were interchanged in comparison with the mainshock. They proposed that this phenomenon was a result of a difference in hydrostatic pressure between the region of the largest aftershock and that of the mainshock, resulting from geographic peculiarities of the hypocentral locations and a stress redistribution which

Vol. 41, No. 3, 1993 
made the former maximum stress direction the new minimum stress direction and causing the former intermediate and minimum stresses directions to become the new maximum and intermediate stress directions, respectively. Comparing Fig. 1c with Fig. 9 , we can see that the western end of the mainshock source area reaches to the mountainous area on Izu Peninsula. Thus, there is possibility that the hydrostatic pressure of the mainshock source area was somewhat different from the region of greatest reduction in surficial area-strain (region of coarse stippling on map view of Fig. 9) in the time prior to the occurrence of the mainshock.

Thus, there was a large stress redistribution which resulted in the occurrence of L-type events near the ends of the mainshock fault plane, with P-and/or T-axes which had extremely different directions from that of the mainshock. Preexisting planes of weakness may have caused this, although the report of the Research Group for Active Faults of Japan (1991) cites no notable fault in the region.

There are two possible sources for the slight variations in the P-and T-axes of the 'aftershock'-type events from those of the mainshock if this observation is statistically significant. First, there may have been a temporary rotation of the effective environmental stress from the tectonic stress direction, and second, some directions may have become more easy to rupture as a result of the occurrence of the mainshock. Zoback et al. (1987) reported that along the San Andreas fault system, the angle between the strike of an extremely weak fault and the direction of the maximum principal stress near the fault was $30-40^{\circ}$ different from the angle between the fault strike and the far-field maximum principal stress direction. Jones (1988) and Oppenheimer et al. (1988) also reported that the existence of weak faults affects the stress field near the San Andreas fault. Further, Jones (1988) reported that the stress field near the fault might vary temporally. We cannot adopt any of these explanations directly to our study area because the mainshock source area is under very different conditions from the San Andreas fault system. However, the fact that a preexisting fault affects the stress field near a mainshock source area supports the first possible cause, above.

On the other hand, Koide and Bhattacharji (1977) and Koide (1983) proposed that a large fault is composed of an interconnected set of smaller fractures or faults aligned en echelon. Further, Fukao and Furumoto (1985) also reported that a fault plane at one scale is segmented into blocks of statistically similar size by barriers of statistically similar heights. These proposals suggest that aftershocks, generated through fracturing the unfractured part of the mainshock source area, could belong to a set of smaller en echelon faults. The set of smaller faults is proposed to have some dominant strike that is slightly different from that of the mainshock, and have less frictional strength than the surrounding rock. Thus, we can postulate that smaller faults, of discordant strikes, can be reactivated and enlarged through the fracturing of the material between them, prior to the fracturing of a new fault (e.g., Scholz, 1990, pp. 100-101). Thus, the strike of aftershock nodal planes and their P-and $\mathrm{T}$-axes would be somewhat different from those of the mainshock. This explanation supports the second possible cause discussed above. We do not, however, have enough data to discuss this deviation of stress axis azimuths quantitatively.

The variations in the nodal planes of the 'aftershock'-type events may also be due to the same causes as those for the variation in the orientation of the stress axes. A 
study of the 1984 Western Nagano Prefecture earthquake (Nagano-Ken-Seibu Godo-Zisin Kansoku-Han, 1988), reported that even though aftershock P- and T-axis azimuths were different from those of the mainshock, the strike of one of the nodal planes of each aftershock cluster was nearly equal to that of the mainshock. This common strike was interpreted as reflecting structures in the crust. In our study the strikes are not quite as similar, so the crustal structure is not likely to be the cause of the nodal plane variations in any simple manner.

Gephart and Forsyth (1984) reported the possibility that the aftershocks of the $M_{\mathrm{b}} 6.2$ San Fernando earthquake of 1971 occurred on preexisting zones of weakness of any orientation under the uniform stress present in the source region. In our case, magma intrusion and penetration are related to the activity studied because of the submarine eruption, and there are no notable active faults in the area where the seismic activity occurred. In addition, considerable crustal deformations directly related to the activity was observed (Okada and Yamamoto, 1991). Thus, we conclude that the observed features in the seismicity were mainly induced by stress redistribution due to the intrusion and penetration of magma and the occurrence of aftershocks of the $M_{\mathrm{L}}$ 5.5 event.

The dominance of S-type events in the region from 1979-1989 suggests that the tectonic stress field is stable over a period of ten years. Thus, the changes in the focal mechanisms of the aftershocks is due to a disturbance of the local stress field or a result of local crustal structure. Further, the clustering of T-axes in a narrower azimuth band suggests that the study area was, on the average, in a tensional tectonic stress field during the study period.

The subsequent occurrence of R-type events suggests that the study area changed from a tensional to a compressional stress field after our study period.

Ooida et al. (1989) reported that the aftershocks of the strike-slip 1984 Western Nagano Prefecture earthquake (central Japan, $M_{\mathrm{L}}$ 6.8) were mainly strike-slip immediately after the mainshock, but later, some aftershocks of the reverse type were observed in a zone where swarm earthquakes had occurred since 1976; the swarm earthquakes were mainly of the reverse type. They proposed that the mainshock had reactivated the swarm activity and that the reverse-type aftershocks had belonged to it. In and around our study area, we also had swarm activity starting on June 30, 1989. The swarm activity was studied by Matsumura et al. (1991) and Tohoku University (1990) and these earthquakes were mainly of S-type. Thus, if the effects of the mainshock were the same as that proposed by Ooida et al. (1989), events other than those of the S-type were not directly related to the previous swarm activity.

\section{Conclusions}

The hypocentral distribution and focal mechanism solutions result in the following conclusions. First, the segregation of the $\mathrm{S}$ - and $\mathrm{N}$-type events suggests that the magma that took part in the submarine eruption penetrated into the mainshock source area and primarily filled the deeper part of its eastern half, and induced the tensile stress field around it. In addition, the tensile stress entered the $4.2 \mathrm{~km} / \mathrm{s}$ layer to a depth of about $1.5 \mathrm{~km}$ after the largest aftershock; this is supported by the S-P time and the

Vol. 41 , No. 3, 1993 
P-wave first motions observed at OSK. The tensile stress diminished rapidly after the end of the study period, about three days after the occurrence of the submarine eruption. Second, the tectonic stress field in the region where the surficial area-strain is expected to have been most reduced by the mainshock, was possibly disturbed by the mainshock; this is supported by the occurrence of L-type events in the area, assuming that the hydrostatic pressure of the area was different from that of the mainshock source area due to geographical peculiarities.

The P- and S-wave arrival times and P-wave first motions at JIZ, NRY, HTS, and YGW were obtained from NIED with the help of S. Matsumura and M. Imoto. The use of data of YGW was permitted by $\mathrm{K}$. Ishibashi of Building Research Institute. The use of P- and S-wave arrival times and $\mathrm{P}$-wave first motions from HOK was permitted by M. Mizoue of ERI. The construction of the temporary stations of the MRI was assisted by the Hotel Caisson and the Shogetsuin Temple. The colleagues of MRI, JMA, and the Meteorological College helped us in many situations.

This study is a part of the routine research program of the MRI entitled "Basic Research on Seismic Activity and the Generation Mechanism in the Crust," and of a five-year project entitled "A Study on Prediction of Destructive Intraplate Earthquakes, Part 2."

K. Fujita of Michigan State University and two anonymous reviewers greatly helped us improve this manuscript.

\section{REFERENCES}

Aki, K., Earthquake generating stress in Japan for the years 1961 to 1963 obtained by smoothing the first motion radiation patterns, Bull. Earthq. Res. Inst., Univ. Tokyo, 44, 447-471, 1966.

Celerier, B., How much does slip on a reactivated fault plane constrain the stress tensor?, Tectonics, 7, 1257-1278, 1988.

Crampin, S. and J. H. Lovell, A decade of shear-wave splitting in the earth's crust: what does it mean? what use can we make of it? and what should we do next?, Geophys. J. Int., 107, 387-407, 1991.

Earthquake Research Institute (ERI, University of Tokyo) and Meteorological Research Institute (MRI, Japan Meteorological Agency), Seismic activities in the Izu Peninsula and its vicinity (May-October, 1989), Rep. Coord. Comm. Earthq. Predict., 43, 157-173, 1990 (in Japanese).

Fukao, Y. and M. Furumoto, Hierarchy in earthquake size distribution, Phys. Earth Planet. Inter., 37, 149-168, 1985.

Gephart, J. W. and D. W. Forsyth, An improved method for determining the regional stress tensor using earthquake focal mechanism data: application to the San Fernando earthquake sequence, J. Geophys. Res., 89, 9305-9320, 1984.

Herrmann, R. B., FASTHYPO-a hypocenter location program, Earthq. Notes, 50, 25-37, 1979.

Honda, H., Earthquake mechanism and seismic waves, J. Phys. Earth, 10, 1-87, 1962.

Ida, Y. and M. Mizoue (eds.), Seismic and volcanic activity in and around the Izu Peninsula and its tectonic implications (Special Issue), J. Phys. Earth, 39, 1-460, 1991.

Ikami, A., Underground structure of Shizuoka prefecture, Programme and abstracts, Seismological Society of Japan, No. 2, 125, 1977 (in Japanese).

Japan Meteorological Agency, Seismic activity in and around the Izu peninsula (May-October, 
1989), Rep. Coord. Comm. Earthq. Predict., 43, 140-156, 1990 (in Japanese).

Jones, L. M., Focal mechanisms and the state of stress on the San Andreas fault in southern California, J. Geophys. Res., 93, 8869-8891, 1988.

Kaneshima, S., Origin of crustal anisotropy: shear wave splitting studies in Japan, J. Geophys. Res., 95, 11121-11133, 1990.

Kaneshima, S., M. Ando, and S. Crampin, Shear-wave splitting above small earthquakes in the Kinki district of Japan, Phys. Earth Planet. Inter., 45, 45-58, 1987.

Kasahara, J., H. Katao, S. Koresawa, and M. Takahashi, Undersea seismic observation of 1989 volcano-seismic activity, off Ito, Izu Peninsula, central Japan, J. Phys. Earth, 39, 107-130, 1991.

Koide, H., Seismotectonic problem of en echelon fault system and earthquake source mechanism, Chigaku Zasshi, 92, 33-52, 1983 (in Japanese).

Koide, H. and S. Bhattacharji, Geometric patterns of active strike-slip faults and their significance as indicators for areas of energy release, in Energetics of Geodynamic Processes, ed. S. K. Saxena and S. Bhattacharji, pp. 46-66, Springer-Verlag, Berlin, 1977.

Ma, K.-F. and H. Kanamori, Aftershock sequence of the 3 December 1988 Pasadena earthquake, Bull. Seismol. Soc. Am., 81, 2310-2319, 1991.

Maritime Safety Agency, Hydrographic Department, Submarine topographic change related to submarine volcano eruption at Teisi Knoll off Ito in the eastern coast of Izu Peninsula, Rep. Coord. Comm. Earthq. Predict., 43, 323-329, 1990 (in Japanese).

Matsumura, S., T. Ohkubo, and M. Imoto, Seismic swarm activity in and around the Izu Peninsula preceding the volcanic eruption of July 13, 1989, J. Phys. Earth, 39, 93-106, 1991.

McKenzie, D. P., The relation between fault plane solutions for earthquakes and the directions of the principal stresses, Bull. Seismol. Soc. Am., 59, 591-601, 1969.

Mochizuki, E., K. Sakuma, and M. Imoto, Focal mechanisms of earthquakes in the Kanto-Tokai district (1979-1983), Zisin, Ser. 2, 38, 411-422, 1985 (in Japanese).

Nagano-Ken-Seibu Godo-Zisin Kansoku-Han, Distribution of focal mechanism, Chikyu Monthly, 10, 693-699, 1988 (in Japanese).

National Research Center for Disaster Prevention (NRCDP), An interpretation of off Ito earthquake swarm and submarine volcanic activities in 1989, Rep. Coord. Comm. Earthq. Predict., 43, 200-205, 1990 (in Japanese).

Odaka, T., M. Seino, and A. Yoshida, Stress fields due to strike-slip faults, tensile faults and cylindrical soft bodies, and related seismic activities, Pap. Meteorol. Geophys., 42, 105-126, 1991.

Okada, Y. and E. Yamamoto, A model for the 1989 seismo-volcanic activity off Ito, central Japan, derived from crustal movement data, J. Phys. Earth, 39, 177-195. 1991.

Ooida, T., F. Yamazaki, I. Fujii, and H. Aoki, Aftershock activity of the 1984 Western Nagano Prefecture earthquake, central Japan, and its relation to earthquake swarms, J. Phys. Earth, 37, 401-416, 1989.

Oppenheimer, D. H., P. A. Reasenberg, and R. W. Simpson, Fault plane solutions for the 1984 Morgan Hill, California, earthquake sequence: evidence for the state of stress on the Calaveras fault, J. Geophys. Res., 93, 9007-9026, 1988.

Oshima, S., M. Tsuchide, S. Kato, S. Okubo, K. Watanabe, K. Kudo, and J. Ossaka, Birth of a submarine volcano "Teisi Knoll," J. Phys. Earth, 39, 1-19, 1991.

Pechmann, J. C. and H. Kanamori, Waveforms and spectra of preshocks and aftershocks of the 1979 Imperial Valley, California, earthquake: evidence for fault heterogeneity?, J. Geophys. Res., 87, 10579-10597, 1982.

Vol. 41, No. 3, 1993 
Research Group for Active Faults of Japan, Active Faults in Japan: Sheet Maps and Inventories (revised edition), the University of Tokyo Press, Tokyo, 363 pp., 1991.

Rybicki, K., T. Kato, and K. Kasahara, Mechanical interaction between neighboring active faults-static and dynamic stress field induced by faulting, Bull. Earthq. Res. Inst., Univ. Tokyo, 60, 1-21, 1985.

Sato, R. and M. Matsu'ura, Strains and tilts on the surface of a semi-infinite medium, J. Phys. Earth, 22, 213-221, 1974.

Scholz, C. H., The Mechanics of Earthquakes and Faulting, Cambridge University Press, Cambridge, 439 pp., 1990.

Seno, T., The instantaneous rotation vector of the Philippine Sea plate relative to the Eurasian plate, Tectonophysics, 42, 209-226, 1977.

Tohoku University, Faculty of Science, Earthquake swarm off the east coast of the Izu Peninsula caused by volcanic eruption of the Teishi seamount, Rep. Coord. Comm. Earthq. Predict., 43, 182-189, 1990 (in Japanese).

Tsukahara, $H$. and T. Ikeda, Crustal stress orientation pattern in the central part of Honshu, Japan-stress provinces and their origins, J. Geol. Soc. Jpn., 97, 461-474, 1991 (in Japanese).

Tsukahara, H. and Y. Kobayashi, Crustal stress in the central and western parts of Honshu, Japan, Zisin, Ser. 2, 44, 221-231, 1991 (in Japanese).

Ukawa, M., Collision and fan-shaped compressional stress pattern in the Izu block at the northern edge of the Philippine Sea plate, J. Geophys. Res., 96, 713-728, 1991.

Yamakawa, N., M. Kishio, and I. Maeda, Aftershocks of the Tokachi-oki earthquake of 1968 (II)-spatial and temporal distributions of the aftershocks and the focal mechanisms of the main shock and major aftershocks, Geophys. Mag., 36, 53-73, 1972.

Yamaoka, K., H. Watanabe, and S. Sakashita, Seismicity during the 1986 eruption of Izu-Oshima volcano, Kazan, Ser. 2, 33, Special Issue, 91-101, 1988 (in Japanese).

Yoshii, T., S. Asano, S. Kubota, Y. Sasaki, H. Okada, T. Masuda, H. Murakami, S. Suzuki, T. Moriya, N. Nishide, and H. Inatani, Detailed crustal structure in the Izu Peninsula as revealed by explosion seismic experiments, J. Phys. Earth, 34, Suppl., S241-S248, 1986.

Zoback, M. D., M. L. Zoback, V. S. Mount, J. Suppe, J. P. Eaton, J. H. Healy, D. Oppenheimer, P. Reasenberg, L. Jones, C. B. Raleigh, I. G. Wong, O. Scotti, and C. Wentworth, New evidence on the state of stress of the San Andreas fault system, Science, 238, 1105-1111. 1987. 